Elsevier required licence: (C) $<2020>$. This manuscript version is made available under the CC-BY-NCND 4.0 license http://creativecommons.org/licenses/by-nc-nd/4.0/

The definitive publisher version is available online at

[https://linkinghub.elsevier.com/retrieve/pii/S2214993720301020] 


\section{Atmospheric-pressure plasma seawater desalination: clean energy, agriculture, and resource recovery nexus for blue planet}

U. G. Mihiri Ekanayake, ${ }^{\mathrm{a}, \mathrm{b}}$, Dong Han $\mathrm{Seo}^{\mathrm{c}^{*}}$, Konstantin Faershteyn ${ }^{\mathrm{a}, \mathrm{b}}$, Anthony P. O’Mullane ${ }^{\mathrm{a}, \mathrm{b}}$, Hokyong Shon $^{\mathrm{c}}$, Jennifer Macleod ${ }^{\mathrm{a}, \mathrm{b}}$, Kostya (Ken) Ostrikov ${ }^{\mathrm{a}, \mathrm{b}^{*}}$

${ }^{a}$ School of Chemistry and Physics, Science and Engineering Faculty, Queensland University of Technology (QUT), Brisbane, QLD, 4000, Australia

${ }^{\mathrm{b}}$ Centre for Materials Science, Queensland University of Technology (QUT), Brisbane, QLD, 4000, Australia

${ }^{\mathrm{c}}$ Centre for Technology in Water and Wastewater, School of Civil and Environmental Engineering, University of Technology Sydney (UTS), P. O. Box 123, 15 Broadway, NSW 2007, Australia

${ }^{*}$ Corresponding author e-mail: kostya.ostrikov@qut.edu.au

${ }^{*}$ Co-corresponding author e-mail: Michaeldonghan.seo@uts.edu.au 


\title{
Atmospheric-pressure plasma seawater desalination: clean energy, agriculture, and resource recovery nexus for blue planet
}

\begin{abstract}
Water connects every aspect of life. Only 4\% of the world's water is fresh water, where most of water sources have different degrees of salinity. As a result, billions of people around the globe face water scarcity which is a global challenge. Desalination technologies which separate the fresh water from the solvated salts ions in saline water are attracting major attention. However, conventional desalination processes including thermally and pressure driven processes are highly energy intensive. To address this issue, here we report that the atmospheric-pressure plasma (APP) treatment of saline water can be a new potential alternative low-energy and green desalination route. Meanwhile, valuable salts are recovered by direct salt crystal precipitation within a short plasma processing time. During desalination and salt precipitation, plasma activated desalinated water (PADW) is generated and can be used for clean energy generation by water splitting and sustainable agriculture by enhanced plant seed germination. In turn, functional nanomaterials can be extracted from the precipitated salt. The PADW exhibited low salinity of $5.6 \mathrm{~ms} / \mathrm{cm}$ with low $\mathrm{pH}$ value of 2.1. The unique intrinsic PADW chemistries further enhanced the electrochemical water splitting in both hydrogen evolution reaction (HER) at a Pt electrode and oxygen evolution reaction (OER) at a $\mathrm{RuO}_{2}$ electrode compared with the conventional acidic solution of similar $\mathrm{pH}$. Moreover, the feasibility of using PADW in sustainable agriculture was demonstrated by enhancing mungbean seed germination using tap water mixed with PADW. At optimum mix concentration, both seed germination rates and germination percentages increased. Finally, we demonstrated the feasibility of synthesis of high-value 2D nanomaterials exemplified by $\mathrm{Mg}(\mathrm{OH})_{2}$ nanosheets via single step thermal process using the salt precipitated from the seawater by the plasma process. Combined with straightforward use of renewable electricity to generate APPs, this study reveals the plasma potential for sustainable recovery of clean water, clean energy generation, sustainable agriculture, and manufacturing of advanced functional nanomaterials - all from the greatest treasure of our blue planet - seawater.
\end{abstract}

Keywords: Atmospheric-pressure plasma, Desalination, Water splitting, Seed germination, Nanocrystals 


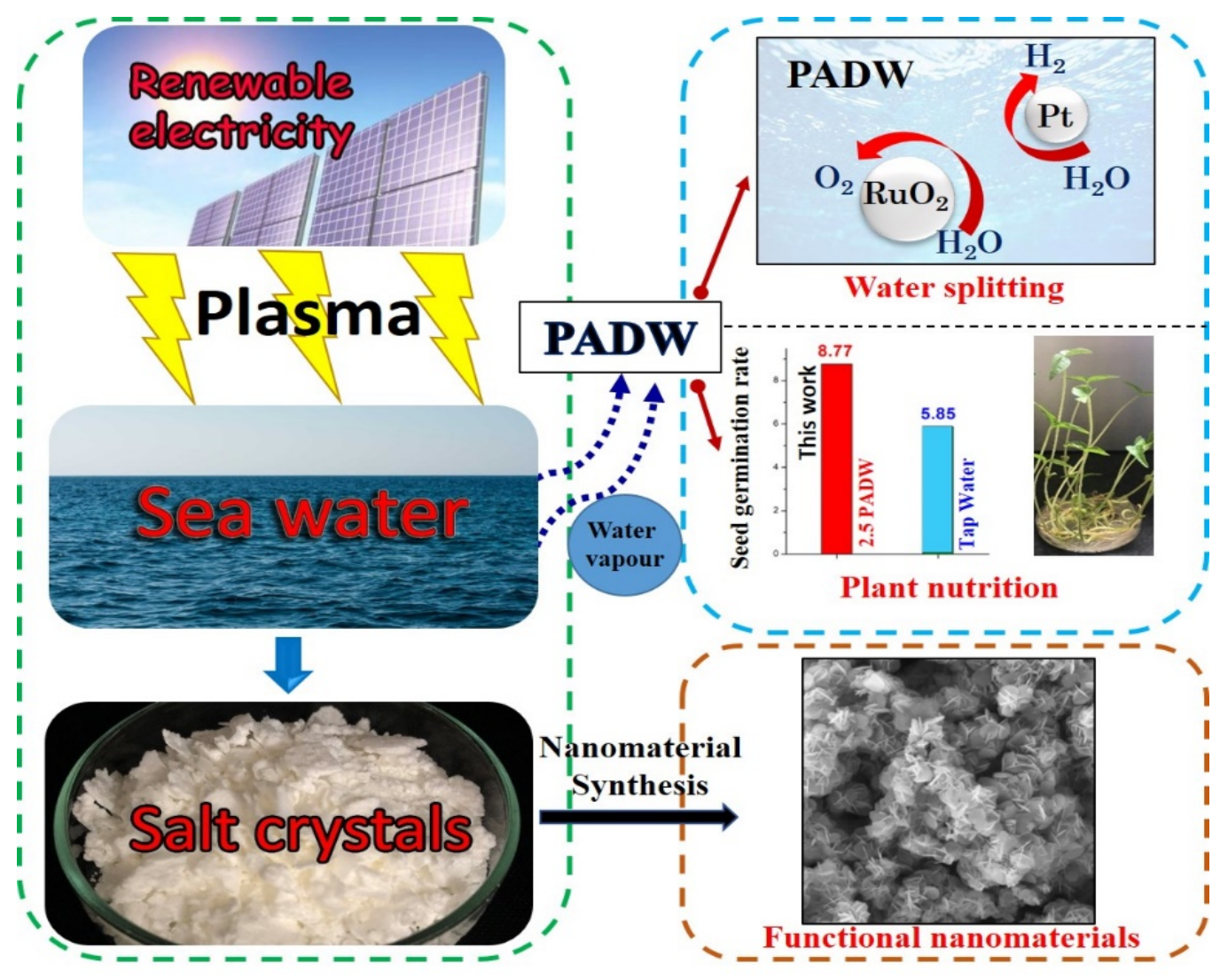




\section{Introduction}

Most of water sources (94-97\%) around the globe are saline [1]. Collectively, oceans make up a "giant blue planet", with water being the main yet severely underutilized resource [2]. Therefore, recently the sustainable exploitation of the ocean's resources known as "blue economy" has become an intense topic of research as a solution for the water scarcity and exhaustion of terrestrial minerals [3]. As seawater can be the source of a vast amount of fresh water, desalination of seawater has gained immense attention as a solution for the increasing global demand of fresh water [4]. Among the several desalination processes, multi-stage flash distillation (MFD), multiple-effect distillation (MED), membrane distillation (MD), and reverse osmosis (RO) are commonly used to separate fresh water from salt water $[5,6]$.

These methods can be divided into two main categories, namely, thermally driven and pressure driven technologies $[6,7]$. Pressure driven, reverse osmosis is the most commonly used desalination process and currently the lowest energy consumption amongst the mentioned desalination processes [8, 9]. However, RO processes usually leave behind hypersaline solutions to be disposed or treated which often creates environmental issues. In MFD and MED thermally driven desalination processes, seawater is heated to an elevated temperature and the resultant vapour is condensed either through a membrane or a condenser to obtain clean potable water. However, thermal desalination processes are much more energy intensive as they require the liquid to vapour transition. Hence, there is a strong need for alternative low energy and green processes for desalination [10-12].

Atmospheric pressure plasmas (APPs), which can be sustainably powered from renewable (e.g., solar or wind) electricity, have attracted great attention for diverse applications including materials synthesis, spectroscopic analysis, gas treatment, surface treatment, medicine and biotechnology [13-15]. APPs offer unique advantages such as low cost, low energy consumption, ease of implementation with versatility. Atmospheric pressure, non-equilibrium plasmas generate $\mathrm{O}_{3}$, UV photons and various reactive oxygen and nitrogen species (RONS) [16-19]. The interaction between gas phase plasmas and saline water produces unique chemistries driven by the electric field strength, ion charges, UV radiation 
and other species present in the plasma. The reactive species generated in the gas phase interact with solvated charged salts and water to induce numerous physico-chemical transformations including precipitation of solid salt crystals in seawater demonstrated in this work. Subsequently, ions produced from APP penetrate through the gas-liquid interface and subsequently produce secondary species reacting with the water $[20,21]$. The $\mathrm{NO}_{x}, \mathrm{OH}$ radicals, $\mathrm{O}, \mathrm{O}_{3}$, hydroxides and $\mathrm{H}_{2} \mathrm{O}_{2}$ originated in the plasma can produce secondary species such as $\mathrm{NO}_{3}^{-}, \mathrm{NO}_{2}{ }^{-}$, and $\mathrm{H}_{2} \mathrm{O}_{2}$.

Several studies have been conducted by discharging plasma on water surface to produce plasma activated water (PAW) [16, 22]. In most cases, PAW has been used for microbial inactivation [23, 24], food preservation [25, 26], enhanced seed germination [22, 25], and biomedical applications [27]. Plasma has also been used to enhance the desalination efficiency of the membranes in the membrane distillation processes [28-31]. Different plasmas such as dielectric barrier discharge and corona discharge have been used to remove pharmaceutical contaminants in water [32, 33]. Apart from the unique chemistry, APP also it carries energy to effectively and rapidly evaporate water well below the boiling point [34].

Herein, with observation of unique direct salt crystal formation inside a saline seawater in a liquid phase [Supplementary Video S1], we utilize this phenomenon to desalinate saltwater while imparting interesting chemistry and generate plasma activated desalinated water (PADW). To the best of our knowledge, this is the first systematic study on using atmospheric pressure plasmas to desalinate natural seawater and further utilize the PADW in clean energy generation, sustainable agriculture and recovery of valuable advanced functional materials. Moreover, APP is a simple and energy efficient method to evaporate water faster compared to conventional thermal heating, and to induce effective crystallization at ambient conditions. Salt crystal formation was achieved within only a few seconds of plasma discharging on the seawater surface. The evaporated water is both desalinated and plasma activated (PADW) upon the plasma discharge while valuable salts crystals are separated. The PADW and the recovered salt can be used in electrocatalytic water splitting, enhanced seed growth, and synthesis of advanced functional nanomaterials with two-dimensional (2D) structure. 
Electrocatalytic water splitting to produce hydrogen and oxygen demands, when coupled with electricity generated by wind or solar, is an eco-friendly and sustainable approach to address the ever increasing energy demands [35-39]. Recently, intense research has focused on new catalysts material for energy efficient $\mathrm{H}_{2}$ and $\mathrm{O}_{2}$ production [40, 41]. However, much less attention was given to water-based electrolytes. Often mixtures of deionized (DI) water with acidic solutions are used as an electrolyte in the $\mathrm{H}_{2}$ and $\mathrm{O}_{2}$ generation processes. In such aspect, PADW could be used directly for water splitting for both the HER and the OER showing its potential for use in the clean energy sector where potable water could be a limited resource and the production of hydrogen at a scale, using seawater. Although plasmas have previously been used to develop high performance catalysts, such as Ni-Fe foam, carbon doped $\mathrm{Co}_{3} \mathrm{O}_{4}$, hierarchical $\mathrm{NiFeOx} / \mathrm{NiFeP}$ and $\mathrm{Ni}_{3} \mathrm{~S}_{2}-\mathrm{FeS}-\mathrm{CoS}$ nanosheets for electrocatalytic water splitting, to best of our knowledge, this is the first systematic work demonstrating the potential of plasma activated desalinated water (PADW) in HER and OER processes which offer advantages over conventional acidic media [42-47].

We further investigate the role of PADW in plant growth and seed germination, thus being a potentially versatile tool for sustainable agriculture. Previously, enhanced seed germination of mung beans in aqueous solutions has been observed when atmospheric pressure, dielectric barrier discharge (DBD) air plasmas $\left(\mathrm{N}_{2}, \mathrm{He}\right.$, air and $\left.\mathrm{O}_{2}\right)$ were directly discharged on the seeds for 10 minutes [22]. Moreover, plasma activated water (PAW), made using transient electric spark, has also affected wheat germination including seed growth, photosynthetic pigments, soluble proteins and antioxiadant enzyme activity [25]. The enhanced seed germination in PAW can be attributed to the chemical composition, especially the reactive nitrogen and oxygen species (RNOS). In this work, we also demonstrate the enhanced seed germination of mung beans in the optimized PADW medium.

Finally, to complete the sustainable plasma-enabled, potentially zero-waste cycle, we utilized the precipitated salt crystals from the plasma desalination process in the synthesis of two dimensional (2D) $\mathrm{Mg}(\mathrm{OH})_{2}$ nanoparticles. 


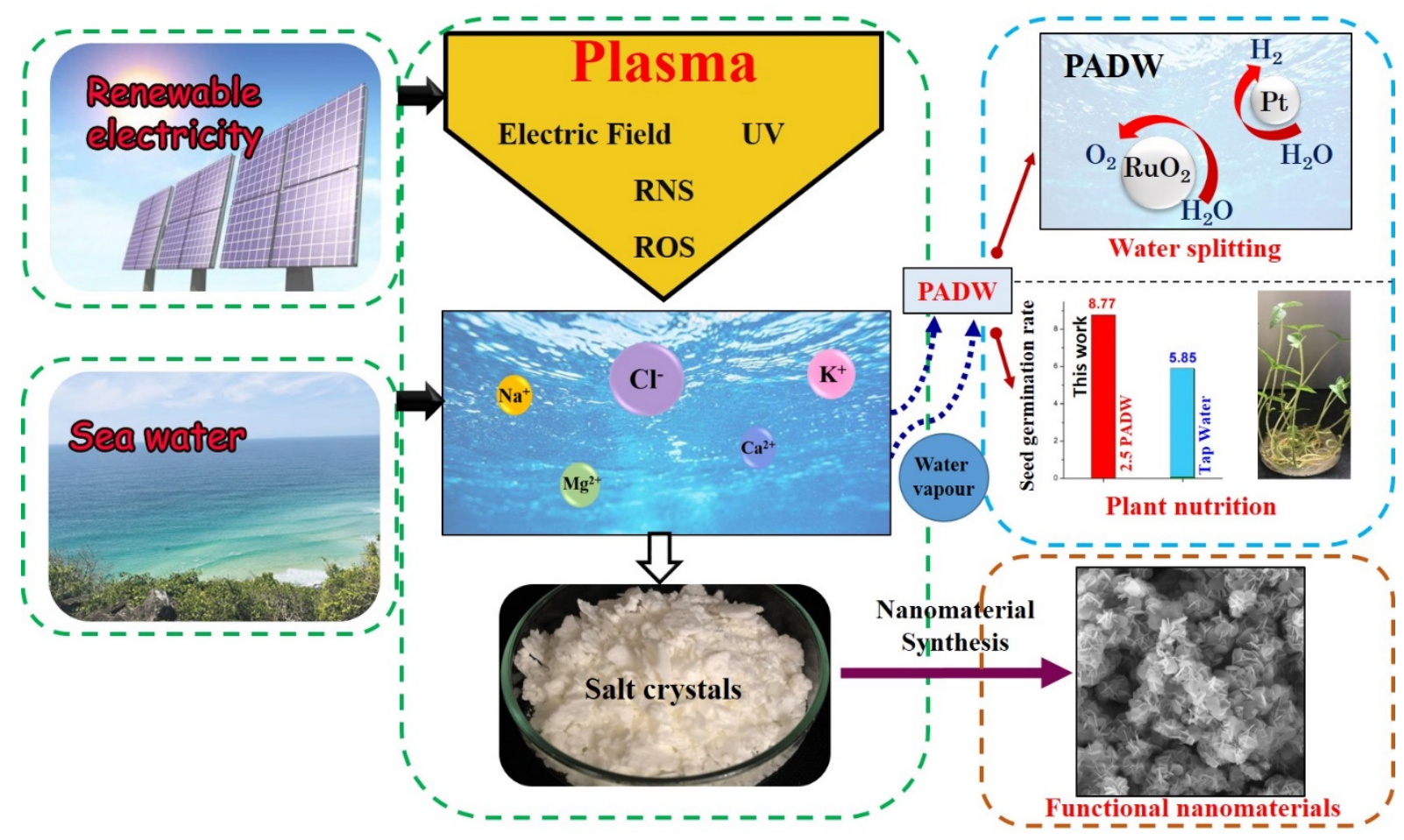

Figure 1. Sustainable plasma process for plasma assisted seawater desalination and crystallization and its application in sustainable energy generation and agriculture: The concept, Key features and the applications. Plasma, which can be produced using renewable energy, exposed onto seawater resulting in PADW and enable the recovery of crystalline salt. In turn, PADW resulted in highly efficient electrocatalytic water splitting and it also enhanced seed germination and the growth. The precipitated crystalline salt were also used to prepare high value two dimensional functional nanomaterials.

\section{Materials and Methods}

\subsection{Materials}

All the chemical reagents were of analytical grade (Sigma-Aldrich) and used as received without further purification: Potassium permanganate $\left(\mathrm{KMnO}_{4}, 97 \%\right)$, Sulfuric acid $\left(\mathrm{H}_{2} \mathrm{SO}_{4}, 36 \sim 38 \%\right.$,), Nafion 117 solution, iso-propanol (99.7\%), Ruthenium (IV) oxide $\left(\mathrm{RuO}_{2}, 99.9 \%\right)$, and Nitric acid $\left(\mathrm{HNO}_{3}, 68-70 \%\right)$.

\subsection{Atmospheric pressure plasma system}

The atmospheric pressure plasma system consists of a digitized plasma generator (PG-1000 ZE) and an air compressor (FP-290). The air compressor is connected to the plasma generator to introduce 
atmospheric air and all the plasma treatments were done at $3.0 \mathrm{~L} / \mathrm{min}$ atmospheric air flow. In a typical plasma activated desalination process, the plasma torch of maximum $1 \mathrm{kWh}$ power with average 0.5 $\mathrm{kWh}$ was inserted into a $250 \mathrm{~mL}$ three-necked round bottom flask through its centre neck. A thermometer and a water-cooled condenser were connected to the other two side-necks of the same flask. The solution, which needs to be plasma treated $(50 \mathrm{~mL})$ was added into the flask and APP was discharged on the solution keeping a fixed distance between the water surface and the tip of the plasma torch.

\subsection{Preparation of PADW from sea water}

The seawater sample used in this work was collected from the Gold Coast, Queensland, Australia (28 1' 0 ' South, $153^{\circ} 24^{\prime} 0^{\prime}$ East). A three-necked round bottom flask was added with sea water (50 $\left.\mathrm{mL}\right)$ and APP was discharged on the solution while the temperature was being monitored with time. The evaporated water was collected as plasma activated desalinated water (PADW) into a flask using a watercooled condenser. The salt crystals precipitated up on the plasma discharge were separated into another flask. A similar experiment was conducted using thermal energy instead of the plasma to boil and evaporate sea water $(50 \mathrm{~mL})$. The evaporated water was condensed the same way and collected to another flask. The concentrations of anion and cation species were measured in the seawater and PADW samples. The $\mathrm{pH}$, conductivity and $\mathrm{H}_{2} \mathrm{O}_{2}$ concentration were determined in the initial and collected solutions via condensation. The $\mathrm{H}_{2} \mathrm{O}_{2}$ concentration was determined titrimetrically using $\mathrm{KMnO}_{4}$.

\section{4. $\mathrm{RuO}_{2}$ ink preparation}

Deionized water $(3.98 \mathrm{~mL})$, Nafion $(20 \mu \mathrm{L})$, iso-propanol $(1 \mathrm{~mL})$ were mixed with $5 \mathrm{mg}$ of $\mathrm{RuO}_{2}$ catalyst and the mixture was sonicated for $15 \mathrm{~min}$ to make the $1 \mathrm{mg}$ of $\mathrm{RuO}_{2}$ in $1 \mathrm{~mL}$ of ink solution. Then 10 $\mu \mathrm{L}$ of that ink was dropped on the glassy carbon disc and air-dried, and this was repeated two more times to get $30 \mu \mathrm{L}$ of the ink drop coated on the electrode.

\subsection{Electrochemical measurements}

PADW brought down to room temperature was used to study its applicability in electrocatalytic water splitting for both the HER and OER. All the electrochemical measurements were recorded with a three- 
electrode system at room temperature using a Biologic VMP3B-20 workstation operated by the EC-Lab software. The CV measurements were taken in PADW solution to investigate the improvements in the OER and HER processes. The $\mathrm{pH}$ of the PADW was measured to be 2.1. Distilled water was brought to $\mathrm{pH}=2$ with $\mathrm{HNO}_{3}$ was used as the control. Each solution was purged with $\mathrm{N}_{2}(\mathrm{~g})$ for 20 min prior to the $\mathrm{CV}$ measurements. An $\mathrm{Ag} / \mathrm{AgCl}$ leak-less reference electrode (eDAO Pty Ltd) and Pt wire electrodes (Bioanalytical systems, Inc) were used as the reference and counter electrodes respectively. For the HER $\mathrm{CV}$ experiments, a Pt rotating disc electrode was used as the working electrode (area of $0.07 \mathrm{~cm}^{2}$, Bioanalytical Systems, Inc). For the OER CV experiments, a rotating ring disc electrode (RRDE), (Pt ring/glassy carbon (GC) disc, $\mathrm{GC}$ disc coated with $\mathrm{RuO}_{2}$ ) was used as the working electrode. The geometric area of the $\mathrm{RuO}_{2}$ coated GC disc $\left(0.07 \mathrm{~cm}^{2}\right)$ and Pt ring electrodes $\left(0.1884 \mathrm{~cm}^{2}\right)$ were used to calculate the current density and confirm OER was occurring. The potential values of all the electrochemical data were converted to the reversible hydrogen electrode (RHE) scale using the following formula, $\mathrm{RHE}=\mathrm{E} \mathrm{Ag} / \mathrm{AgCl}+0.059 \mathrm{pH}+0.197 \mathrm{~V}$. The current density was normalized to the geometric surface area of the electrode.

\subsection{Effects of PADW on seed germination}

A seed germination study was carried out over 16 consecutive days. Uniformly sized Mung beans (20 in count) purchased from a local supermarket, Brisbane, Australia, were spread on a filter paper in a petri dish. Several solutions spiked with varying amounts of PADW were prepared in tap water as given in the Table 1 and added to each petri dish. The germination percentage was observed at $3 \mathrm{~h}$ intervals for $36 \mathrm{~h}$. In order to keep the seeds moistened and to facilitate the germination, each petri dish was added with $5 \mathrm{~mL}$ of the respective solution at each $5 \mathrm{~h}$ interval. The germination percentage and germination rate were calculated according to the equations given below.

Germination percentage $=$ Number of germinated seeds $/$ Number of seeds per petri dish

$$
\text { Seed germination rate }=\left(\sum_{i=1}^{k} f i / \sum_{i=1}^{k} f i x i\right) 100
$$


where $f_{\mathrm{i}}$ is the number of seeds newly germinated at the hour $i, x i$ is the number of hours from $100 \%$ germination, and $k$ is the last hour of $100 \%$ germination. The seeds were considered as germinated when a radicle with minimum length of $1 \mathrm{~mm}$ emerged from the seed.

Table 1. Amount of DPAW and tap water added to each Petri dish with mung bean seeds

\begin{tabular}{|c|l|l|l|l|l|l|l|}
\hline \multicolumn{2}{|c|}{ Petri dish } & Control & E1 & E2 & E3 & E4 & E5 \\
\hline \multirow{2}{*}{$\begin{array}{c}\text { Solution } \\
\text { composition }\end{array}$} & Amount of DPAW (mL) & 0 & 2.5 & 5 & 10 & 20 & 50 \\
\cline { 2 - 9 } & Amount of tap water (mL) & 50 & 47.5 & 45 & 40 & 30 & 0 \\
\hline \multicolumn{2}{|c|}{$\mathrm{pH}$} & 7.2 & 3.5 & 3.2 & 2.9 & 2.6 & 2.2 \\
\hline
\end{tabular}

\subsection{Synthesis of 2D $\operatorname{Mg}(\mathrm{OH})_{2}$ nanoparticles}

Salt (100 g) separated from seawater via discharging atmospheric pressure plasma was crushed using a mortar and pestle to make a fine powder. The resulted powder was mixed with $20 \mathrm{~mL}$ of ethanol and placed in a furnace and annealed at $400{ }^{\circ} \mathrm{C}$ for $1 \mathrm{~h}$ at a rate of $2{ }^{\circ} \mathrm{C} \mathrm{min}-1$ under Ar atmosphere in order to synthesis $2 \mathrm{D} \mathrm{Mg}(\mathrm{OH})_{2}$ nanostructures. The final product was washed with distilled water to remove unreacted salt and the mixture was centrifuged several times to separate the nanoparticles.

\section{Characterization techniques}

The conductivity of the solutions was measured using FiveGo ${ }^{\mathrm{TM}}$ conductivity meter. The concentration of anion and cation in the seawater and PADW was measured using DIONEX D22100 RFCI ion chromatograph (IC) and inductively coupled plasma emission spectroscopy (ICP-OES), respectively. The morphologies of the salt crystals and synthesized nanomaterials were observed using a scanning electron microscope (SEM, Tescan MIRA 3) coupled with energy dispersive X-ray spectrometer (EDX) analyses. The chemical composition of the crystals and the synthesized nanomaterial was examined on an X-ray photoelectron spectroscope (XPS) (Kratos AXIS Supra photoelectron spectrometer). X-ray diffraction (XRD) spectra were recorded using Bruker D8 with CuKa line ( $a=1.5418 \AA$ ).

\section{Results and discussion}

\subsection{Physicochemical properties of PADW}



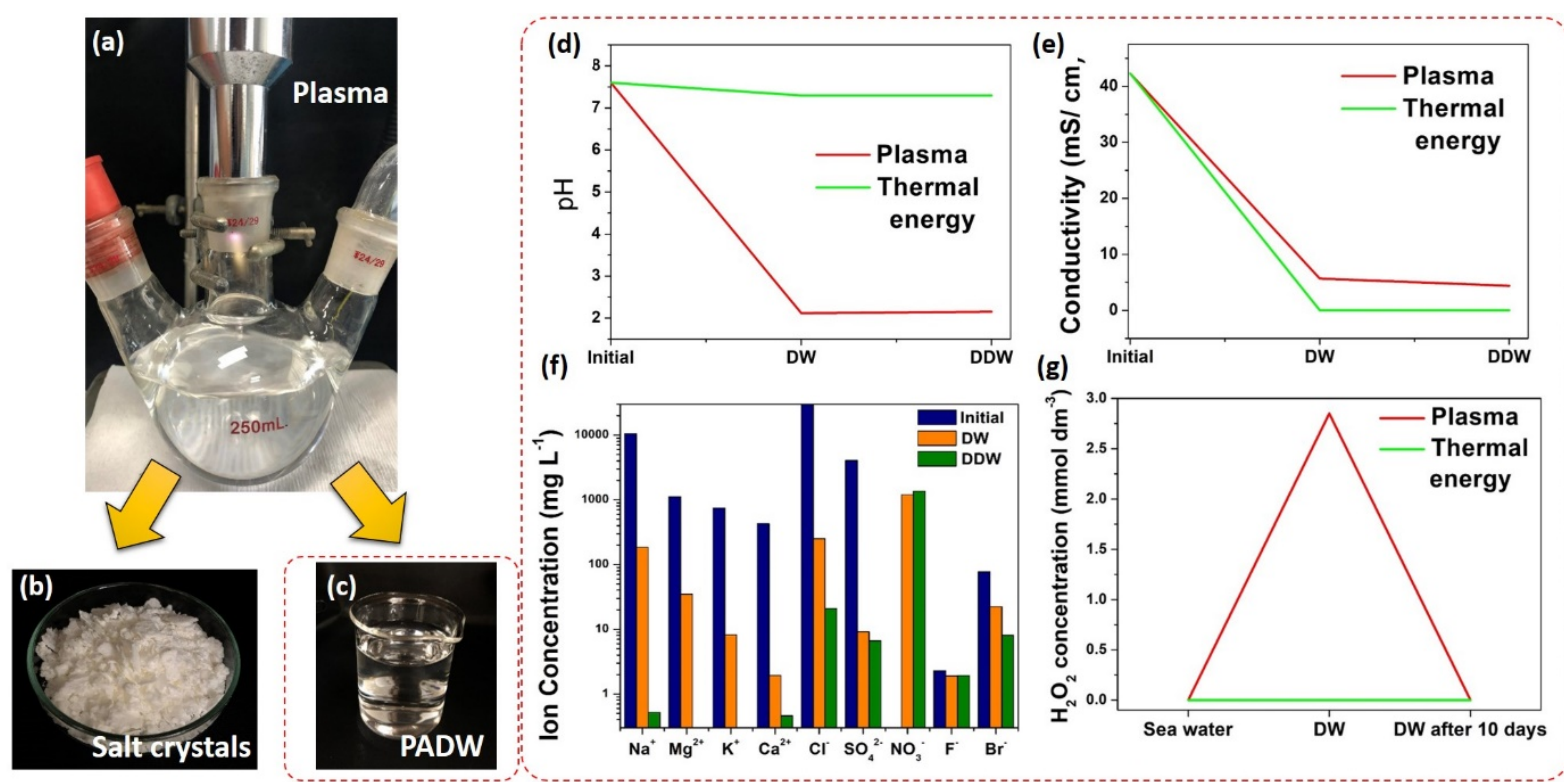

Figure 2. Exposure of seawater to atmospheric pressure plasma (APP) produces crystalline salt and plasma activated desalinated water (PADW). (a) APP torch; (b) salt crystals; (c) PADW; Variation of (d) $\mathrm{pH}$ and (e) conductivity of initial, desalinated water (DW) and double desalinated water (DDW) produced from seawater using plasma and thermal energy. (f) Different ion concentrations of initial seawater, DW and DDW produced using APP as the energy source (g) The $\mathrm{H}_{2} \mathrm{O}_{2}$ concentration of seawater, DW and DW after 10 days produced using APP and thermal energy.

Plasma activated desalinated water (PADW) was collected by condensing the vapour evolving from seawater exposed to the atmospheric pressure plasma and the precipitating salt crystals were collected from the flask at the end of the plasma discharge process (Figure 2). This PADW had retained unique chemical properties as a result of plasma-seawater interactions. Figures 2a-c, depict the APP torch, crystalline salt yielded and the PADW, respectively. When the APP was discharged on the seawater, the temperature of the solution increased to $75{ }^{\circ} \mathrm{C}$ rapidly within $\sim 10$ min (Figure S1) and the water evaporation occurred due to the heat released during the plasma interaction with seawater. This complex and dynamic plasma interaction resulted in salt crystal formation within the seawater [Supplementary Video S1] and enhanced precipitation of salt crystals during the evaporation process. Moreover, we observed effective evaporation of seawater at a relatively lower temperatures compared to the distilled water produced from the conventional thermal heating process where it usually requires bringing the water to the boiling temperature. This effect could arise from the unique features of the atmospheric 
pressure plasma process. The desalination and crystal formation efficiency can be controlled by varying the distance from the plasma nozzle to the solution surface and this is a subject of our ongoing work on determining the doses of plasma exposure in various plasma activated media.

Through the plasma interaction with seawater, we aimed to desalinate seawater and generate plasma activated desalinated water with reactive radicals. Hence, the effectiveness of the desalination process and the effect of plasma in seawater were evaluated by measuring the change in conductivity, $\mathrm{pH}, \mathrm{H}_{2} \mathrm{O}_{2}$ concentration and ion concentration of initial untreated seawater (initial), desalinated seawater (DW) and the double desalinated water (DDW). The DDW represents a collected PADW treated with the same plasma again. The values were further compared to a distilled water solution collected using a conventional heating process. DW and DDW showed lower conductivity $(5.68,4.40 \mathrm{mS} / \mathrm{cm}$ in DW and DDW of plasma) compared to the original salt solution $(42.30 \mathrm{mS} / \mathrm{cm})$ (Figure 2e). This clearly demonstrates the lower salt concentration in the condensates in the DW and DDW, indicating an effective desalination has taken place.

Interestingly, the water desalinated using plasma showed higher conductivity $(5.68 \mathrm{mS} / \mathrm{cm})$ compared to water desalinated using thermal energy $(0.05 \mathrm{mS} / \mathrm{cm})$ (Figure 2e). This could be attributed to the formation of various active species from reactions between plasma and $\mathrm{H}_{2} \mathrm{O}$ molecules at gas-liquid interface and also during the plasma evaporation, solvated ions form a complex structure with water vapour and being transported together to the vapour phase $[16,18]$. In this work cold atmospheric pressure plasma (CAPP) is used to evaporate the saline solutions. In CAPP the typical temperature of the electrons $\left(T_{e} \sim 10,000-40,000 \mathrm{~K}\right)$ is much higher than the temperature of other heavier species $\left(T_{h} \sim\right.$ 300-1000 K) [54]. When the plasma interacts with the water surface, non-equilibrium evaporation happens, by increasing the temperature to only $\sim 75^{\circ} \mathrm{C}[34]$. The high energy ions from the plasma, interact with the surface of the saline solution and these ions can help break the bonds in the solvated ions species and water molecules from the liquid surface, reducing the energy barrier for the evaporation leading to a phase change to the gaseous vapour form [34]. This gaseous vapour is then condensed and collected as plasma activated desalinated water (PADW). When only thermal energy is used to evaporate 
the solution, the water usually requires higher temperature $\left(100{ }^{\circ} \mathrm{C}\right)$ for the boiling to occur under predominantly equilibrium conditions. It is likely that the higher conductivity of PADW is a result of plasma-assisted generation of ions derived from water (e.g., protons, hydroxide, peroxide, etc.) and possibly less effective removal of ions derived from inorganic salt.

It was observed that the $\mathrm{pH}$ of the plasma treated solutions (DW, DDW) went down from 7.60 to 2.12, respectively, as shown in Figure 1d. This is attributed to the formation of nitrate and nitric acids formed in the solution via the reaction between $\mathrm{H}_{2} \mathrm{O}$ with $\mathrm{NO}_{x}$ species generated in the plasma [16] along with a potential hydrogen peroxide generation from the water interaction with reactive oxygen species from the plasmas. The conductivity and $\mathrm{pH}$ variation were further evaluated by analysing the cation and anion concentrations of the initial seawater, DW and DDW, produced using APP as the energy source (Figure 2f). Analysis revealed a significant reduction in ion concentrations in the DW and DDW, which is the reason for lower conductivity. It is noteworthy that DW and DDW still contained a small amount of salt ions due to the non-equilibrium evaporation. In addition to that, $\mathrm{NO}_{3}{ }^{-}$ions were observed in the DW (1194.59 $\mathrm{mg} \mathrm{L}^{-1}$ ) and DDW (1366.59 $\mathrm{mg} \mathrm{L}^{-1}$ ) solutions which were not present in the initial sea water.

It is well known that the nitrites and nitrates are formed in air plasma treated solutions through the dissolution of nitrogen oxides formed in the air plasma by gas-phase reactions of $\mathrm{N}_{2}$ and $\mathrm{O}_{2}$ (Eq 1-7), along with the formation of $\mathrm{NO}_{2}^{-}$and $\mathrm{NO}_{3}{ }^{-}$in the plasma treated water (Eq 8-11) [16, 20, 21, 55]. The dissolution of $\mathrm{NO}_{\mathrm{x}}$ in water produces $\mathrm{H}^{+}$ions (protons) thereby increasing the acidity (Eq 8-11). When oxidizing agents like $\mathrm{H}_{2} \mathrm{O}_{2}$ and $\mathrm{O}_{3}$ present in the solution $\mathrm{NO}_{2}{ }^{-}$easily converts to $\mathrm{NO}_{3}{ }^{-}$which is the most stable form of $\mathrm{NO}_{x}$. Hence, $\mathrm{NO}_{2}^{-}$ions are not detected owing to their low stability $[15,56]$.

$$
\begin{aligned}
& \mathrm{N}_{2}+\mathrm{e}^{-} \rightarrow \cdot \mathrm{N}+\cdot \mathrm{N}+\mathrm{e}^{-} \\
& \mathrm{e}^{-}+\mathrm{O}_{2} \rightarrow \cdot \mathrm{O}+\cdot \mathrm{O}+\mathrm{e}^{-} \\
& \mathrm{N}+\mathrm{O} \rightarrow \mathrm{NO} \\
& \mathrm{NO}+\mathrm{O} \rightarrow \mathrm{NO}_{2} \\
& \mathrm{NO}+\mathrm{O}_{3} \rightarrow \mathrm{NO}_{2}+\mathrm{O}_{2} \\
& 2 \mathrm{NO}_{2} \leftrightarrow \mathrm{N}_{2} \mathrm{O}_{4}
\end{aligned}
$$




$$
\begin{aligned}
& \mathrm{NO}+\mathrm{NO}_{2} \leftrightarrow \mathrm{N}_{2} \mathrm{O}_{3} \\
& \mathrm{NO}_{2}(\mathrm{aq})+\mathrm{NO}_{2}(\mathrm{aq})+\mathrm{H}_{2} \mathrm{O}(\mathrm{l}) \rightarrow \mathrm{NO}_{2}^{-}{ }_{(\mathrm{aq})}+\mathrm{NO}_{3}{ }_{(\mathrm{aq})}+2 \mathrm{H}^{+}{ }_{(\mathrm{aq})} \\
& \mathrm{NO}{ }_{(\text {aq) }}+\mathrm{NO}_{2} \text { (aq) }+\mathrm{H}_{2} \mathrm{O}_{(\mathrm{l})} \rightarrow 2 \mathrm{NO}_{2}^{-}{ }_{(\text {(aq })}+2 \mathrm{H}^{+}{ }_{(\text {aq })} \\
& \mathrm{NO}_{2}^{-}+\mathrm{O}_{3} \rightarrow \mathrm{NO}_{3}^{-}+\mathrm{O}_{2} \\
& \mathrm{NO}_{2}{ }^{-}+\mathrm{H}_{2} \mathrm{O}_{2}+\mathrm{H}^{+} \rightarrow \mathrm{NO}_{3}{ }^{-}+\mathrm{H}_{2} \mathrm{O}+\mathrm{H}^{+}
\end{aligned}
$$

Figure $1 \mathrm{f}$ gives the $\mathrm{H}_{2} \mathrm{O}_{2}$ concentration in natural seawater, DW and DW sample kept for 10 days after the plasma treatment. $\mathrm{H}_{2} \mathrm{O}_{2}$ was not observed in the initial natural seawater sample. When APP is discharged on natural seawater sample, hydrogen peroxide is generated $\left(2.85 \mathrm{mmol} \mathrm{dm}^{-3}\right)$. The precursor for the formation of $\mathrm{H}_{2} \mathrm{O}_{2}$ is hydroxyl radicals $(\cdot \mathrm{OH})$ [25]. $\mathrm{H}_{2} \mathrm{O}_{2}$ can be formed in the plasma and liquid phases. In the plasma phase, $\mathrm{H}_{2} \mathrm{O}_{2}$ can be generated either from recombination of two hydroxyl radicals or from the reaction between excited water molecule and hydroxyl radical (Eq 12,13) [21]

$$
\begin{aligned}
& \cdot \mathrm{OH}+\cdot \mathrm{OH} \rightarrow \mathrm{H}_{2} \mathrm{O}_{2} \\
& \cdot \mathrm{OH}+\mathrm{H}_{2} \mathrm{O}^{*} \rightarrow \mathrm{H}_{2} \mathrm{O}_{2}+\cdot \mathrm{H}
\end{aligned}
$$

The $\mathrm{H}_{2} \mathrm{O}_{2}$ species in the plasma treated water may be generated due to $\cdot \mathrm{OH}$ radicals formed in water. Plasma initiated UV propagates into the water, excites and dissociates water molecules into $\cdot \mathrm{OH}$ species (Eq 14-16) [57]. However, after 10 days of the preparation of DW using plasmas, the $\mathrm{H}_{2} \mathrm{O}_{2}$ concentration is substantially reduced in the solution.

$$
\begin{aligned}
& \mathrm{UV}+\mathrm{H}_{2} \mathrm{O} \rightarrow \mathrm{H}_{2} \mathrm{O}^{*} \\
& \mathrm{UV}+\mathrm{H}_{2} \mathrm{O}^{*} \rightarrow \cdot \mathrm{OH}+\cdot \mathrm{H} \\
& \cdot \mathrm{OH}+\cdot \mathrm{OH} \rightarrow \mathrm{H}_{2} \mathrm{O}_{2}
\end{aligned}
$$

\subsection{PADW in water splitting}


After collecting the desalinated water from the atmospheric pressure plasma treatment with natural seawater, collected water was then used as an electrolyte for electrocatalytic water splitting process. The results show that the plasma activated desalinated water (PADW) is more effective in electrocatalytic water splitting compared to the control electrolyte produced by the solution of distilled water incorporated with $\mathrm{HNO}_{3}$ which brought down the solution $\mathrm{pH}$ into 2. The cyclic voltammetric analyses revealed that the PADW which has a $\mathrm{pH}$ of approximately 2 could potentially be used as the electrolyte for the hydrogen evolution reaction (HER) and oxygen evolution reaction (OER) where enhanced hydrogen evolution at a Pt electrode was found when compared to a control solution of distilled water brought to a $\mathrm{pH}=2$ using $\mathrm{HNO}_{3}$. Figure 3a shows the cyclic voltammogram (CV) of HER in PADW, control solution and distilled water (D.water in Figure 3). The current density recorded in the PADW is $-50.85 \mathrm{~mA} / \mathrm{cm}^{2}$ at $-0.40 \mathrm{~V}$ vs. RHE, which is significantly higher than the control solution at -27.08 $\mathrm{mA} / \mathrm{cm}^{2}$ (Figure 3e) It should be noted that the onset potential for the reduction process in PADW is $0.20 \mathrm{~V}$ which can be attributed to a contribution from nitrate reduction which is produced during the plasma activation process.

The OER activity of $\mathrm{RuO}_{2}$ in PADW was analysed using rotating ring disc electrode setup in order to confirm that oxygen is being evolved at the electrode rather than chlorine due to the presence of residual chloride ions in the electrolyte. In this setup when $\mathrm{RuO}_{2}$ on the disc catalyses the OER, the Pt ring electrode will detect any oxygen being liberated from the $\mathrm{RuO}_{2}$ and not detect liberated chlorine. Therefore, the detection of current at the disk can be correlated with activity at the ring electrode, thereby confirming that the current is due to the OER. In PADW a higher current density $\left(10.71 \mathrm{~mA} / \mathrm{cm}^{2}\right)$ and lower overpotential ( $0.26 \mathrm{~V}$ vs. RHE) compared to the control solution of distilled water brought to $\mathrm{pH}$ 2 using $\mathrm{HNO}_{3}$ was measured. (Current density: $7.42 \mathrm{~mA} / \mathrm{cm}^{2}$ overpotential: $0.35 \mathrm{~V}$ vs. RHE). The ring current recorded during the experiment shows that oxygen is evolved at $\mathrm{RuO}_{2}$ at a lower potential than in the control solution and occurs at a potential slightly lower than the large increase in current at the disk. Most of the broad anodic feature seen from 1.2 to $1.55 \mathrm{~V}$ is not associated with the OER and could be related to the oxidation of other components in the PADW. 
The result shows that even though $\mathrm{pH}$ of the control solution resemble the PADW, PADW still exhibited higher electrocatalytic activity with lower over potential in electrocatalytic water splitting (HER and OER reactions), confirming that the low $\mathrm{pH}$ is not the only factor responsible for the enhanced water splitting activity. The enhanced electrocatalytic activity may arise from the presence of different HER and OER activity facilitating ions such as $\mathrm{SO}_{4}{ }^{-2}, \mathrm{OH}^{-}$and hydrogen peroxide groups would enhance the electrolyte conductivity compared to the control electrolyte. These factors may be the reason for the observed differences in HER or OER activities at similar $\mathrm{pH}$ values. Therefore, reactive species generated by the APP processing of seawater and its desalinated water could be a promising electrolyte for the future electrocatalytic water splitting devices [42, 43].

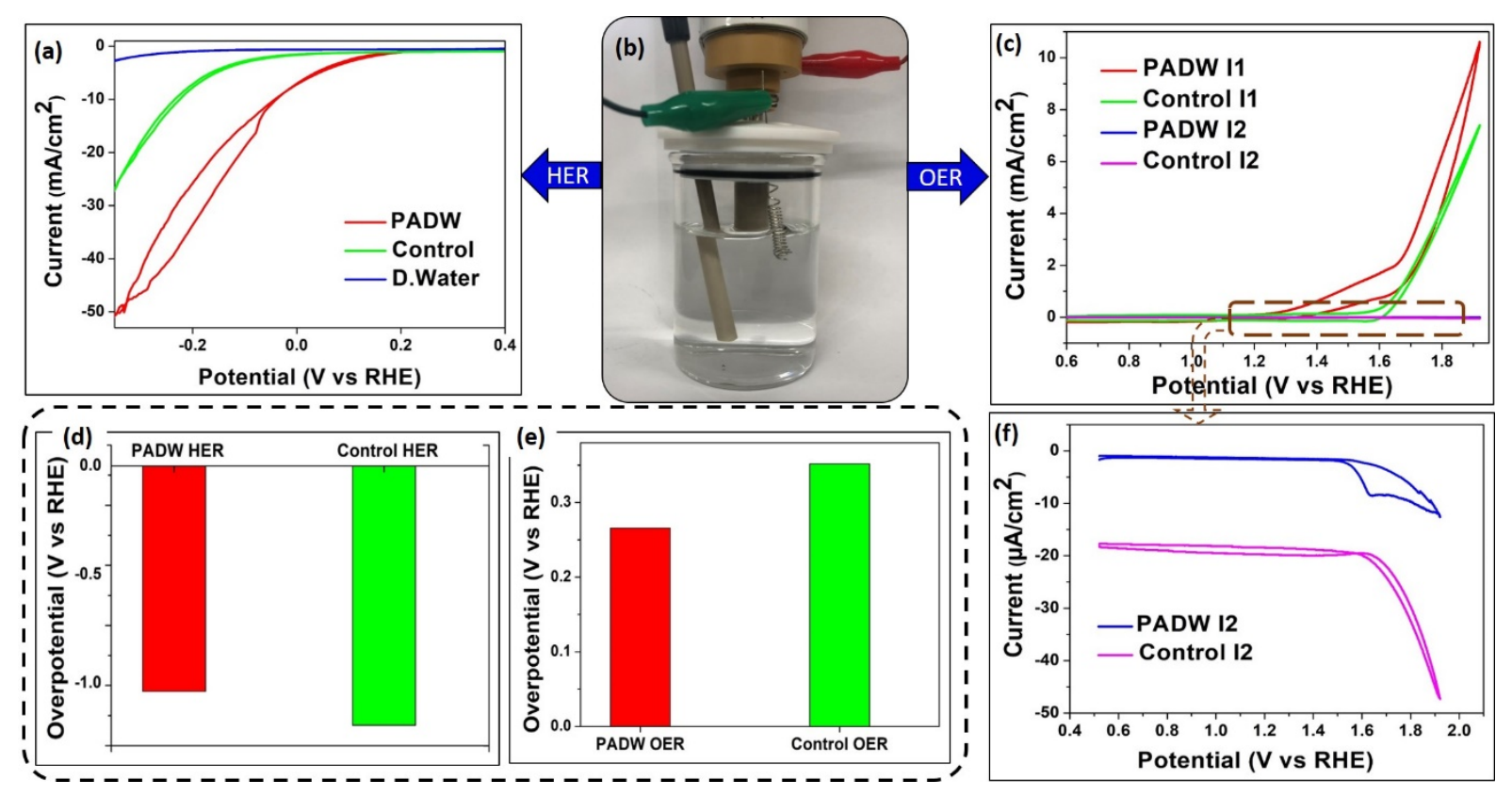

Figure 3. PADW facilitates the efficient water splitting compared to the control solutions in both hydrogen evolution (HER) and oxygen evolution reactions (OER). (a) cyclic voltammograms recorded at the Pt rotating electrode for PADW, control electrolyte and distilled water (D.water) samples at a scan rate of $30 \mathrm{mV} \mathrm{s}^{-1}$; (b) The three-electrode system; (c) cyclic voltammograms recorded at the rotating ring disc electrode $\left(\mathrm{Pt} / \mathrm{RuO}_{2}\right.$ drop coated glassy carbon $(\mathrm{GC})$ ) for PADW and control solution at a scan rate of $30 \mathrm{mV} \mathrm{s}^{-1}$, current density of $\mathrm{RuO}_{2}$ drop coated GC part recorded as I1, and Pt ring part recorded as I2; (d) overpotential values of PADW and control solution for HER; (e) overpotential values of PADW and control solution for OER, and (f) magnified portion of the cyclic voltammograms given in panel (c) of PADW I2 and control 12 comes from Pt ring electrode. 


\subsection{Effect of PADW on seed germination}

To demonstrate the effectiveness of PADW in facilitating the seed germination process, PADW water was added to the normal tap water with different percentages and normal tap water was used as a control to see the effect of PADW on the seed germination. The result shows that mungbeans which were cultivated inside the PADW-spiked water exhibited enhanced seed germination rate and seed germination percentage compared to normal tap water control sample. Figure 3 a-c shows the Mung seedlings in Petri dish E1 (2.5 mL of PADW-spiked water), magnified image of the seedling and the mature Mung plants. Figure 3d represents the germination percentage of Mung beans with varying amounts of PADW. According to Figure 3d, samples with $2.5 \mathrm{~mL}$ (E1) and $5 \mathrm{~mL}$ (E2) of PADW showed $100 \%$ seed germination after $18 \mathrm{~h}$ of incubation with the highest seed germination rate recorded in the sample spiked with $2.5 \mathrm{~mL}$ of PADW.

The reactive oxygen and nitrogen species (RONS) present in the PADW could potentially aid the germination of Mung beans. Previous research has shown that the presence of $\mathrm{NO}_{3}{ }^{-}$ions in the PADW provides the essential nitrogen nutrient for the efficient seed germination [22]. In addition, $\mathrm{H}_{2} \mathrm{O}_{2}$ present in PADW can also enhance the seed germination. Accumulation of $\mathrm{H}_{2} \mathrm{O}_{2}$ in seeds and its positive effect on the germination at the early stages of incubation have been reported in several studies [25]. Appropriate concentration of $\mathrm{H}_{2} \mathrm{O}_{2}$ may stimulate respiration and metabolic activities by the production of $\mathrm{O}_{2}$ during catalase scavenging of $\mathrm{H}_{2} \mathrm{O}_{2}$. Further effects include etching of the seed coating, facilitating water diffusion into the seed, and oxidation of germination inhibitors [25].

However, $50 \mathrm{~mL}$ of PADW without any tap water shows the lowest germination rate indicating the low $\mathrm{pH}$ and presence of high concentration of radicals inside the PADW is not favourable for the seed germination. In addition, higher amount of $\mathrm{NO}_{3}^{-}$in the solution could disrupt nitrogen metabolism in Mung bean sprouts, inhibiting mung bean nodule formation and nitrogen fixation [22]. Another reason for the reduced germination rate of canopy photosynthesis under high nitrogen arise from the overdose 
of nitrogen producing toxic organic nitride, the presence of which damages plant growth $[23,55,58]$. Currently, the nitrate deficiency of plants is a serious issue as it reduces the crop yield, moreover, the fertilizers containing nitrates can act as a pollutant in the soil [59]. The simple plasma activated water can therefore be a promising solution to address such issue, as it can easily be mixed with normal tap water with appropriate dose and applied in the crop field without generating further pollutants in the soil, providing a green alternative solution.

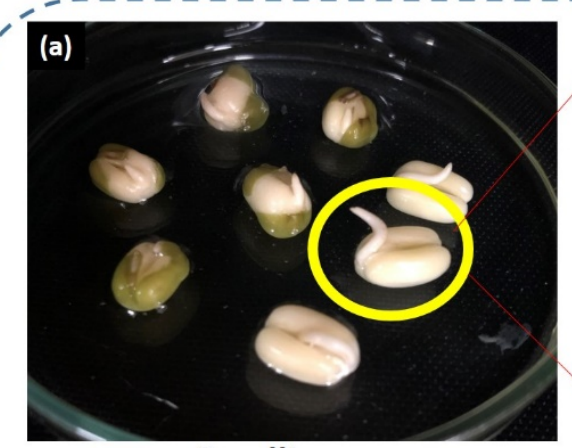

Seedlings

(d)

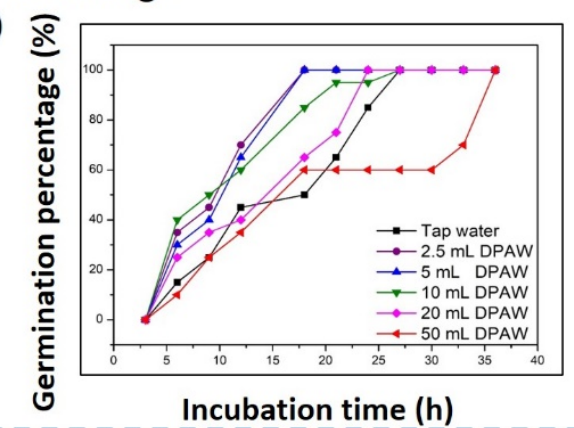

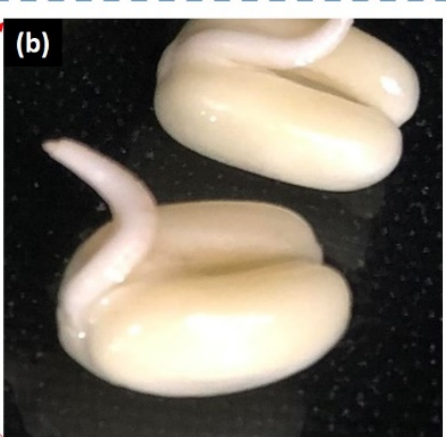

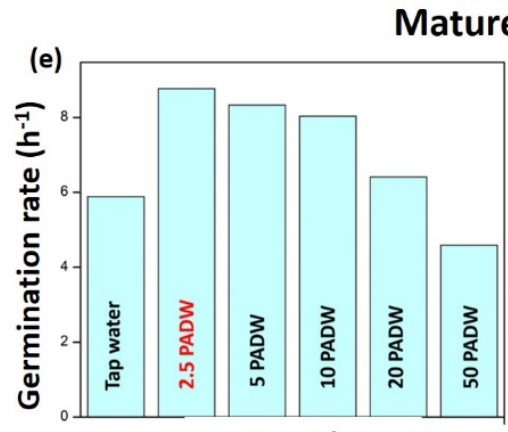

Sample

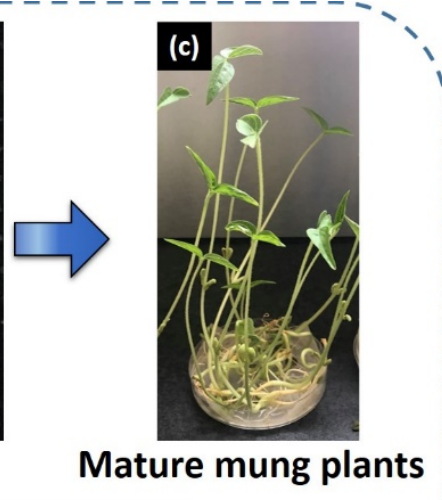

plants

Sample

Figure 4. PADW-added water facilitates enhanced seed germination at the optimal concentration. (a) mung bean seedlings in PADW-added water; (b) magnified images of seedlings; (c) mature mung plants; (d) germination percentage of mung beans; and (e) germination rate of mung beans with varying concentrations of PADW.

\section{4. $2 \mathrm{D} \operatorname{Mg}(\mathrm{OH})_{2}$ nanosheets}

After the collection of the precipitated salts from the plasma desalination process, salt crystals were recovered to produce 2D nanomaterials such as $\mathrm{Mg}(\mathrm{OH})_{2}$ nanosheets. Seawater contains high level of Magnesium which is about $1114 \mathrm{mg} \mathrm{L}^{-1}$ (Figure 2f). $\mathrm{Mg}(\mathrm{OH})_{2}$ 2D nanoparticles were synthesized using the salt precipitated during the plasma discharge process followed by a salt assisted thermal annealing process. Figure 5a is an SEM image of precipitated salt crystals and Figure 5b is a magnified SEM image 
of salt crystals with a cubic shape. XPS spectra of the sea water crystals indicate the Na $1 \mathrm{~S}$ peak at 1071 $\mathrm{eV}$ binding energy and the $\mathrm{Cl}$ peak fit with two sets of spin of $\mathrm{Cl} 2 \mathrm{p}_{3 / 2}$ and $\mathrm{Cl} 2 \mathrm{p}_{1 / 2}$ which confirms the presence of $\mathrm{NaCl}[60]$. XRD analysis was carried out to examine the crystallinity and crystal phase of salt crystals and synthesized product. According to the XRD analysis, in addition to $\mathrm{NaCl}$, the crystals show the presence of corundum and magnesian calcite (Figure S2).

Figure $5 \mathrm{c}$ is an SEM image of synthesized $\mathrm{Mg}(\mathrm{OH})_{2}$ nanoparticles and Figure $5 \mathrm{f}$ is a high resolution image of $\mathrm{Mg}(\mathrm{OH})_{2}$ nanosheets. The thickness of the nanosheets are in the range of $\sim 50 \pm 10 \mathrm{~nm}$ having sharp edges and several micrometres in length with a clean and smooth surface. The XPS spectra of the synthesized $\mathrm{Mg}(\mathrm{OH})_{2}$ are shown in Figure 5f. The XPS spectra clearly indicate the principal Mg KLL Auger peak at binding energy of 300-306 eV [48, 49]. The XRD spectrum analysis shows that the synthesized $\mathrm{Mg}(\mathrm{OH})_{2}$ nanosheets exhibit a hexagonal brucite lattice structure and the sharp and strong intensity of the peaks confirms the produced $\mathrm{Mg}(\mathrm{OH})_{2}$ nanosheets are in crystalline nature (Figure $\mathrm{S} 3$ ) $[53,61]$. Furthermore, the produced $\mathrm{Mg}(\mathrm{OH})_{2}$ nanosheets were analysed by the EDX analysis where clear peaks of $\mathrm{Mg}$ and oxygen were detected further reinforcing the presence of $\mathrm{Mg}(\mathrm{OH})_{2}$ nanosheets (Figure S4).

We emphasize that $\mathrm{Mg}(\mathrm{OH})_{2}$ has unique properties which can be used in broad range of applications such as an antibacterial agent, a neutraliser of acidic water pollutants, fertilizer additive, paper preservative agent, and most importantly as a fire retardant material to incorporate in polymers to reduce the flammability [48-50]. Moreover, many researches have shown that nanostructured $\mathrm{Mg}(\mathrm{OH})_{2}$, such as 2D flower like $\mathrm{Mg}(\mathrm{OH})_{2}$ acted as an excellent flame retardant [51-53]. 

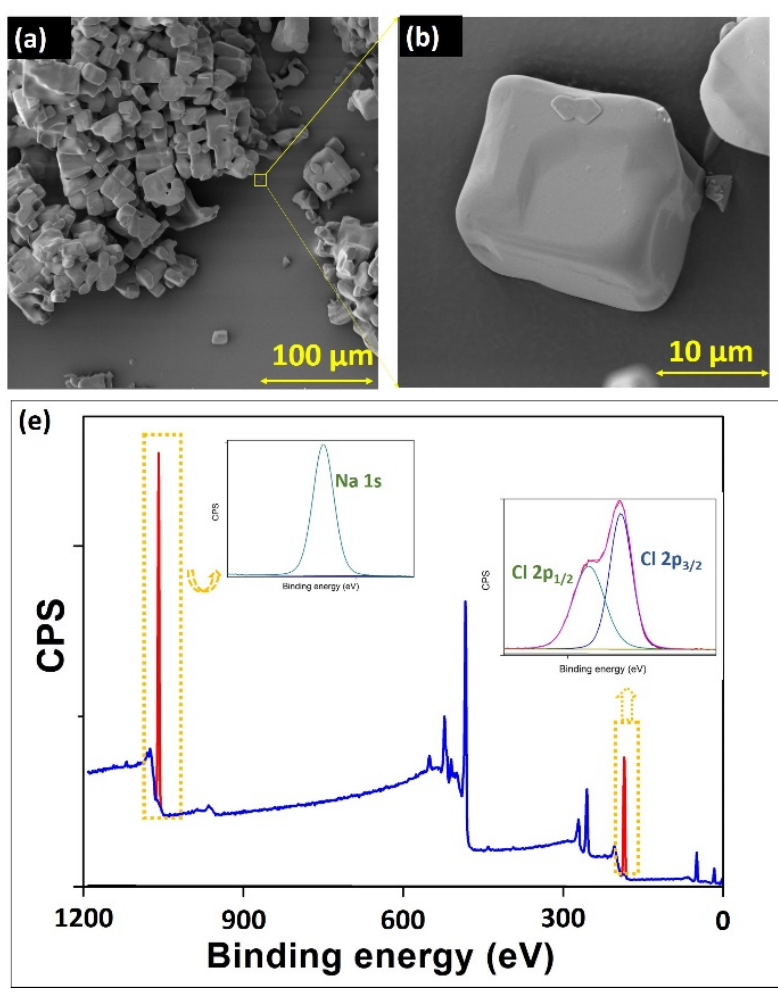
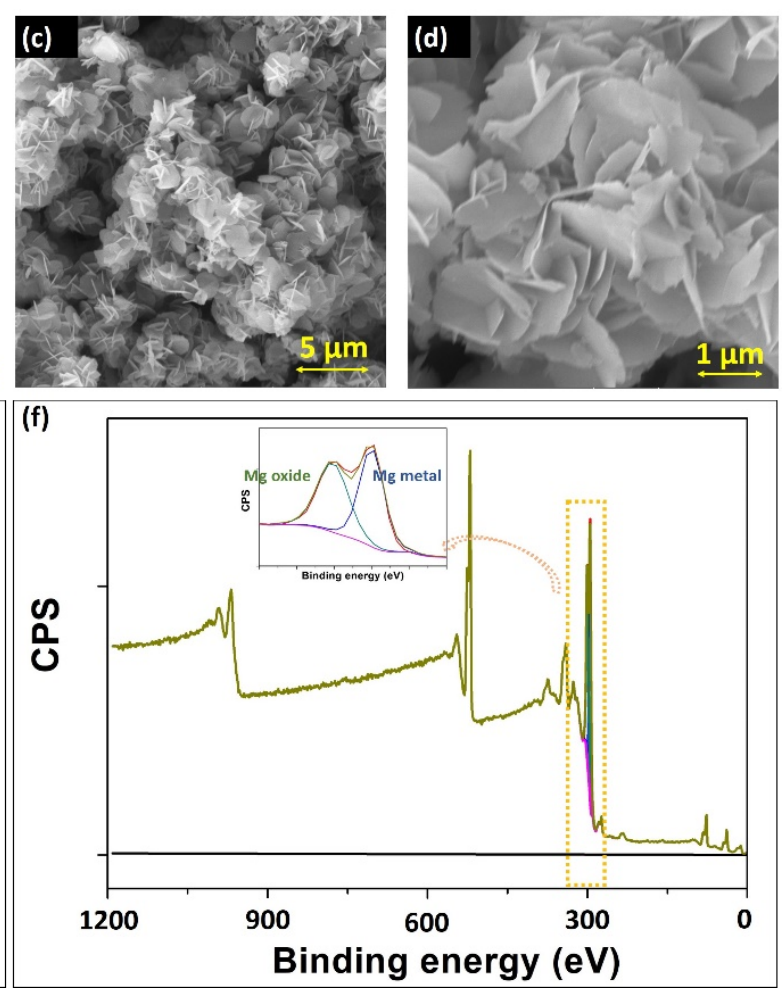

Figure 5. Precipitated $\mathrm{NaCl}$ crystals upon plasma discharge on seawater can be used to synthesize twodimensional (2D) $\mathrm{Mg}(\mathrm{OH})_{2}$ nanosheets. (a) SEM image of precipitated salt; (b) magnified SEM image of precipitated salt; (c) SEM image of synthesized $\mathrm{Mg}(\mathrm{OH})_{2}$ 2D nanosheets; (d) magnified SEM image of $\mathrm{Mg}(\mathrm{OH})_{2}$ 2D nanosheets; (e) XPS spectra of precipitated salt; (f) XPS spectra of synthesized $\mathrm{Mg}(\mathrm{OH})_{2}$ nanosheets.

\section{Conclusion}

Energy efficient desalination and useful salt recovery, energy efficient clean energy generation and sustainable agriculture all represent important topics of research in sustainable energy, materials, and technology fields. In this work, we utilize energy efficient, versatile and cold atmospheric pressure plasma as an effective tool in desalinating the seawater and crystallizing the seawater salts. The PADW exhibited $\mathrm{pH}$ value of $\sim 2.0$ and conductivity value $5.68 \mathrm{mS} / \mathrm{cm}$. Then the separated plasma activated desalinated water (PADW) was collected and used as an electrolyte for HER and OER reactions for electrocatalytic water splitting. The PADW electrolyte enhanced catalytic activities (generation of $\mathrm{H}_{2}$ and $\mathrm{O}_{2}$ at lower overpotential with higher activities) compared to traditional acidic medium (with the same $\mathrm{pH}$ ) used in HER and OER process. Moreover, PADW was mixed with normal tap water to form 
an effective medium for enhanced and rapid seed germination of mung beans compared to the control normal tap water samples. Our results demonstrate that controlled dosage of PADW would be particularly useful in cultivating different type of crops with high yield in near future. Furthermore, the recovered seawater salts were further utilized to synthesize high value $2 \mathrm{D}$ nanomaterials such as $\mathrm{Mg}(\mathrm{OH})_{2}$ nanosheets. This sustainable use of all major seawater components in this work demonstrate that atmospheric pressure plasma is an effective and versatile tool which could bring significant impact in energy efficient desalination, clean energy generation, sustainable agriculture, and manufacturing of advanced functional nanomaterials from recovered inorganic salts.

\section{Acknowledgements}

The authors thank Ms. Jessica Crawford, Mr. Janith Weerasinghe, Dr. Myoung Jun Park, and Dr.

Sanjeewa K. Rodrigo for their technical support and assistance during this work. We acknowledge equipment support from the Central Analytical Research Facility (CARF) operated by the Institute of Future Environment (IFE) at QUT. Partial support by the Australian Research Council (ARC) and QUT's Centre for Materials Science is gratefully acknowledged.

\section{References}

[1] O. Serrano, C. E. Lovelock, B. A. T, P. I. Macreadie, R. Canto, S. Phinn, et al., "Australian vegetated coastal ecosystems as global hotspots for climate change mitigation," Nat Commun, vol. 10, p. 4313, Oct 2 2019. doi.org/10.1038/s41467-019-12176-8

[2] S. Ahmadvand, B. Abbasi, B. Azarfar, M. Elhashimi, X. Zhang, and B. Abbasi, "Looking Beyond Energy Efficiency: An Applied Review of Water Desalination Technologies and an Introduction to CapillaryDriven Desalination," Water, vol. 11, 2019. doi:10.3390/w11040696

[3] K. H. Lee, J. Noh, and J. S. Khim, "The Blue Economy and the United Nations' sustainable development goals: Challenges and opportunities," Environ Int, vol. 137, p. 105528, Jan 312020. doi.org/10.1016/j.envint.2020.105528

[4] B. Gong, H. Yang, S. Wu, G. Xiong, J. Yan, K. Cen, et al., "Graphene Array-Based Anti-fouling Solar Vapour Gap Membrane Distillation with High Energy Efficiency," Nano-Micro Letters, vol. 11, 2019. doi.org/10.1007/s40820-019-0281-1

[5] L. Wu, Z. Dong, Z. Cai, T. Ganapathy, N. X. Fang, C. Li, et al., "Highly efficient three-dimensional solar evaporator for high salinity desalination by localized crystallization," Nat Commun, vol. 11, p. 521, Jan 27 2020. doi.org/10.1038/s41467-020-14366-1

[6] H. Y. Yang, Z. J. Han, S. F. Yu, K. L. Pey, K. Ostrikov, and R. Karnik, "Carbon nanotube membranes with ultrahigh specific adsorption capacity for water desalination and purification," Nat Commun, vol. 4, p. 2220, 2013. DOI: $10.1038 /$ ncomms3220 
[7] K. C. Kang, P. Linga, K.-n. Park, S.-J. Choi, and J. D. Lee, "Seawater desalination by gas hydrate process and removal characteristics of dissolved ions ( $\mathrm{Na}+, \mathrm{K}+, \mathrm{Mg} 2+, \mathrm{Ca} 2+, \mathrm{B} 3+, \mathrm{Cl}-, \mathrm{SO} 42-)$," Desalination, vol. 353, pp. 84-90, 2014. doi.org/10.1016/j.desal.2014.09.007

[8] C. M. Fellows and A. Al-Hamzah, "Thermal Desalination," in Mineral Scales and Deposits, ed, 2015, pp. 583-602. doi.org/10.1016/B978-0-444-63228-9.00023-1

[9] A. Alkhudhiri and N. Hilal, "Membrane distillation-Principles, applications, configurations, design, and implementation," in Emerging Technologies for Sustainable Desalination Handbook, ed, 2018, pp. 55106. doi.org/10.1016/B978-0-12-815818-0.00003-5

[10] D. Brogioli, F. La Mantia, and N. Y. Yip, "Thermodynamic analysis and energy efficiency of thermal desalination processes," Desalination, vol. 428, pp. 29-39, 2018. doi.org/10.1016/j.desal.2017.11.010

[11] D. Brogioli, F. La Mantia, and N. Y. Yip, "Energy efficiency analysis of distillation for thermally regenerative salinity gradient power technologies," Renewable Energy, vol. 133, pp. 1034-1045, 2019. doi.org/10.1016/j.renene.2018.10.107

[12] J. Bundschuh, N. Ghaffour, H. Mahmoudi, M. Goosen, S. Mushtaq, and J. Hoinkis, "Low-cost lowenthalpy geothermal heat for freshwater production: Innovative applications using thermal desalination processes," Renewable and Sustainable Energy Reviews, vol. 43, pp. 196-206, 2015. doi.org/10.1016/j.rser.2014.10.102

[13] H. Hartl, J. MacLeod, A. P. O'Mullane, N. Motta, and K. K. Ostrikov, "Multiscale Plasma-Catalytic OnSurface Assembly," Small, p. e1903184, Aug 21 2019. DOI: 10.1002/smll.201903184

[14] H. Nan, R. Zhou, X. Gu, S. Xiao, and K. Ken Ostrikov, "Recent advances in plasma modification of 2D transition metal dichalcogenides," Nanoscale, vol. 11, pp. 19202-19213, Nov 72019.

[15] M. M. Hossain, Q. H. Trinh, D. B. Nguyen, M. S. P. Sudhakaran, and Y. S. Mok, "Formation of plasmapolymerized superhydrophobic coating using an atmospheric-pressure plasma jet," Thin Solid Films, vol. 675, pp. 34-42, 2019. DOI: 10.1039/c9nr05522c

[16] R. Zhou, R. Zhou, K. Prasad, Z. Fang, R. Speight, K. Bazaka, et al., "Cold atmospheric plasma activated water as a prospective disinfectant: the crucial role of peroxynitrite," Green Chemistry, vol. 20, pp. 5276-5284, 2018. DOI: 10.1039/c8gc02800a

[17] R. Zhou, R. Zhou, P. Wang, B. Luan, X. Zhang, Z. Fang, et al., "Microplasma Bubbles: Reactive Vehicles for Biofilm Dispersal," ACS Appl Mater Interfaces, vol. 11, pp. 20660-20669, Jun 12 2019. DOI: 10.1021/acsami.9b03961

[18] R. Zhou, R. Zhou, Y. Xian, Z. Fang, X. Lu, K. Bazaka, et al., "Plasma-enabled catalyst-free conversion of ethanol to hydrogen gas and carbon dots near room temperature," Chemical Engineering Journal, vol. 382, 2020. doi.org/10.1016/j.cej.2019.122745

[19] R. Zhou, R. Zhou, X. Zhang, K. Bazaka, and K. K. Ostrikov, "Continuous flow removal of acid fuchsine by dielectric barrier discharge plasma water bed enhanced by activated carbon adsorption," Frontiers of Chemical Science and Engineering, vol. 13, pp. 340-349, 2019. doi.org/10.1007/s11705-019-1798-z

[20] S. N. Andreev, L. M. Apasheva, M. K. Ashurov, N. A. Lukina, B. Sapaev, I. B. Sapaev, et al., "Production of pure hydrogen peroxide solutions in water activated by plasma of an electroless microwave discharge and their application for controlling plant growth," Physics, vol. 64, pp. 222-224, 2019. DOI: 10.1134/S1028335819050094

[21] F. Judee, S. Simon, C. Bailly, and T. Dufour, "Plasma-activation of tap water using DBD for agronomy applications: Identification and quantification of long lifetime chemical species and production/consumption mechanisms," Water Res, vol. 133, pp. 47-59, Apr 152018. doi.org/10.1016/j.watres.2017.12.035

[22] R. Zhou, R. Zhou, X. Zhang, J. Zhuang, S. Yang, K. Bazaka, et al., "Effects of Atmospheric-Pressure N2, $\mathrm{He}$, Air, and $\mathrm{O} 2$ Microplasmas on Mung Bean Seed Germination and Seedling Growth," Sci Rep, vol. 6, p. 32603, Sep 1 2016. DOI: 10.1038/srep32603

[23] P. Shaw, N. Kumar, H. S. Kwak, J. H. Park, H. S. Uhm, A. Bogaerts, et al., "Bacterial inactivation by plasma treated water enhanced by reactive nitrogen species," Sci Rep, vol. 8, p. 11268, Jul 262018. DOI:10.1038/s41598-018-29549-6

[24] J. Shen, Y. Tian, Y. Li, R. Ma, Q. Zhang, J. Zhang, et al., "Bactericidal Effects against S. aureus and Physicochemical Properties of Plasma Activated Water stored at different temperatures," Sci Rep, vol. 6, p. 28505, Jun 27 2016. DOI: 10.1038/srep28505 
[25] K. Kucerova, M. Henselova, L. u. Slovakova, and K. Hensel, "Effects of plasma activated water on wheat: Germination, growth parameters, photosynthetic pigments, soluble protein content, and antioxidant enzymes activity," Plasma Processes and Polymers, vol. 16, pp. 1-14, 2018. DOI: 10.1002/ppap.201800131

[26] Y. Zheng, S. Wu, J. Dang, S. Wang, Z. Liu, J. Fang, et al., "Reduction of phoxim pesticide residues from grapes by atmospheric pressure non-thermal air plasma activated water," J Hazard Mater, vol. 377, pp. 98-105, Sep 5 2019. doi.org/10.1016/j.jhazmat.2019.05.058

[27] H. Tanaka, K. Nakamura, M. Mizuno, K. Ishikawa, K. Takeda, H. Kajiyama, et al., "Non-thermal atmospheric pressure plasma activates lactate in Ringer's solution for anti-tumor effects," Sci Rep, vol. 6, p. 36282, Nov 8 2016. DOI: 10.1038/srep36282

[28] L. F. Dumée, H. Alglave, T. Chaffraix, B. Lin, K. Magniez, and J. Schütz, "Morphology-properties relationship of gas plasma treated hydrophobic meso-porous membranes and their improved performance for desalination by membrane distillation," Applied Surface Science, vol. 363, pp. 273285, 2016. doi.org/10.1016/j.apsusc.2015.12.034

[29] L. Eykens, K. De Sitter, S. Paulussen, M. Dubreuil, C. Dotremont, L. Pinoy, et al., "Atmospheric plasma coatings for membrane distillation," Journal of Membrane Science, vol. 554, pp. 175-183, 2018. doi.org/10.1016/j.memsci.2018.02.067

[30] L. Guo, X. Wang, Z. Y. Leong, R. Mo, L. Sun, and H. Y. Yang, "Ar plasma modification of 2D MXene Ti 3 C 2 T x nanosheets for efficient capacitive desalination," FlatChem, vol. 8, pp. 17-24, 2018. doi.org/10.1016/j.flatc.2018.01.001

[31] M. Lee, C. S. Fan, Y. W. Chen, K. C. Chang, P. T. Chiueh, and C. H. Hou, "Membrane capacitive deionization for low-salinity desalination in the reclamation of domestic wastewater effluents," Chemosphere, vol. 235, pp. 413-422, Nov 2019. doi.org/10.1016/j.chemosphere.2019.06.190

[32] A. Sohrabi, G. Haghighat, P. M. Shaibani, C. W. V. Neste, S. Naicker, M. Sadrzadeh, et al., "Degradation of pharmaceutical contaminants in water by an advanced plasma treatment," Desalination and Water Treatment, vol. 139, pp. 202-221, 2019. doi:10.5004/dwt.2019.23297

[33] A. J. Al-Rajab, Z.-U.-I. Mujahid, O. Hakami, M. Albratty, H. A. Alhazmi, and A. M. Hala, "Degradation of acetaminophen in water by using dielectric barrier discharge," Desalination and Water Treatment, vol. 109, pp. 337-342, 2018. doi: 10.5004/dwt.2018.22114

[34] J. B. F. d. O. Barauna, C. S. Pereira, I. A. Gonçalves, J. d. O. Vitoriano, and C. Alves Junior, "Sodium Chloride Crystallization by Electric Discharge in Brine," Materials Research, vol. 20, pp. 215-220, 2017. doi.org/10.1590/1980-5373-MR-2017-0108

[35] J. Huo, Y. Chen, Y. Liu, J. Guo, L. Lu, W. Li, et al., "Bifunctional iron nickel phosphide nanocatalysts supported on porous carbon for highly efficient overall water splitting," Sustainable Materials and Technologies, vol. 22, 2019. doi.org/10.1016/j.susmat.2019.e00117

[36] R. Zhao, D. Cui, J. Dai, J. Xiang, and F. Wu, "Morphology controllable NiCo2O4 nanostructure for excellent energy storage device and overall water splitting," Sustainable Materials and Technologies, 2020. doi.org/10.1016/j.susmat.2020.e00151

[37] J. Mei, T. Liao, L. Kou, and Z. Sun, "Two-Dimensional Metal Oxide Nanomaterials for Next-Generation Rechargeable Batteries," Adv Mater, vol. 29, Dec 2017. DOI: 10.1002/adma.201700176

[38] J. Mei, T. Liao, and Z. Sun, "Two-dimensional metal oxide nanosheets for rechargeable batteries," Journal of Energy Chemistry, vol. 27, pp. 117-127, 2018. doi.org/10.1016/j.jechem.2017.10.012

[39] W. Sun, X. Rui, D. Yang, Z. Sun, B. Li, W. Zhang, et al., "Two-Dimensional Tin Disulfide Nanosheets for Enhanced Sodium Storage," ACS Nano, vol. 9, pp. 11371-11381, 2015.

[40] Y. Dou, T. Liao, Z. Ma, D. Tian, Q. Liu, F. Xiao, et al., "Graphene-like holey Co3O4 nanosheets as a highly efficient catalyst for oxygen evolution reaction," Nano Energy, vol. 30, pp. 267-275, 2016. 10.1021/acsnano.5b05229

[41] Z. Wu, N. Ambrožová, E. Eftekhari, N. Aravindakshan, W. Wang, Q. Wang, et al., "Photocatalytic H2 generation from aqueous ammonia solution using TiO2 nanowires-intercalated reduced graphene oxide composite membrane under low power UV light," Emergent Materials, vol. 2, pp. 303-311, 2019. doi.org/10.1007/s42247-019-00029-5

[42] Q. Zhang, W. Chen, G. Chen, J. Huang, C. Song, S. Chu, et al., "Bi-metallic nitroxide nanodot-decorated tri-metallic sulphide nanosheets by on-electrode plasma-hydrothermal sprouting for overall water splitting," Applied Catalysis B: Environmental, vol. 261, 2020. doi.org/10.1016/j.apcatb.2019.118254 
[43] S. Qu, W. Chen, J. Yu, G. Chen, R. Zhang, S. Chu, et al., "Cross-linked trimetallic nanopetals for electrocatalytic water splitting," Journal of Power Sources, vol. 390, pp. 224-233, 2018. doi.org/10.1016/j.jpowsour.2018.04.061

[44] D. Yan, R. Chen, Z. Xiao, and S. Wang, "Engineering the electronic structure of Co3O4 by carbon-doping for efficient overall water splitting," Electrochimica Acta, vol. 303, pp. 316-322, 2019. doi.org/10.1016/j.electacta.2019.02.091

[45] X. Sun, X. Yang, H. Xiang, H. Mi, P. Zhang, X. Ren, et al., "Nitrogen-doped CoOx/carbon nanotubes derived by plasma-enhanced atomic layer deposition: Efficient bifunctional electrocatalyst for oxygen reduction and evolution reactions," Electrochimica Acta, vol. 296, pp. 964-971, 2019.

doi.org/10.1016/j.electacta.2018.11.084

[46] C. Zhang, N. Gong, C. Ding, Y. Li, W. Peng, G. Zhang, et al., "Plasma-assisted synthesis of threedimensional hierarchical NiFeOx/NiFeP electrocatalyst for highly enhanced water oxidation in alkaline media," International Journal of Hydrogen Energy, vol. 44, pp. 26118-26127, 2019. doi.org/10.1016/j.ijhydene.2019.08.084

[47] L. Du, G. Shi, Y. Zhao, X. Chen, H. Sun, F. Liu, et al., "Plasmon-promoted electrocatalytic water splitting on metal-semiconductor nanocomposites: the interfacial charge transfer and the real catalytic sites," Chemical Science, vol. 10, pp. 9605-9612, 2019. DOI: 10.1039/c9sc03360b

[48] F. Al-Hazmi, A. Umar, G. N. Dar, A. A. Al-Ghamdi, S. A. Al-Sayari, A. Al-Hajry, et al., "Microwave assisted rapid growth of $\mathrm{Mg}(\mathrm{OH}) 2$ nanosheet networks for ethanol chemical sensor application," Journal of Alloys and Compounds, vol. 519, pp. 4-8, 2012. doi:10.1016/j.jallcom.2011.09.089

[49] Y. Luo, Y. Sun, J. Lv, X. Wang, J. Li, and F. Wang, "Transition of interface oxide layer from porous $\mathrm{Mg}(\mathrm{OH}) 2$ to dense $\mathrm{MgO}$ induced by polyaniline and corrosion resistance of $\mathrm{Mg}$ alloy therefrom," Applied Surface Science, vol. 328, pp. 247-254, 2015. doi.org/10.1016/j.apsusc.2014.11.177

[50] Y. Luo, X. Wang, W. Guo, and M. Rohwerder, "Growth Behavior of Initial Product Layer Formed on Mg Alloy Surface Induced by Polyaniline," Journal of The Electrochemical Society, vol. 162, pp. C294-C301, 2015. DOI: $10.1149 / 2.1101506$ jes

[51] P. Loganathan, G. Naidu, and S. Vigneswaran, "Mining valuable minerals from seawater: a critical review," Environmental Science: Water Research \& Technology, vol. 3, pp. 37-53, 2017. DOI: $10.1039 /$ c6ew00268d

[52] M. Ratova, L. Tosheva, P. J. Kelly, and B. Ohtani, "Characterisation and properties of visible light-active bismuth oxide-titania composite photocatalysts," Sustainable Materials and Technologies, vol. 22, 2019. doi.org/10.1016/j.susmat.2019.e00112

[53] J. Mei, G. A. Ayoko, C. Hu, J. M. Bell, and Z. Sun, "Two-dimensional fluorine-free mesoporous Mo2C MXene via UV-induced selective etching of Mo2Ga2C for energy storage," Sustainable Materials and Technologies, vol. 25, 2020. doi.org/10.1016/j.susmat.2020.e00156

[54] C. Tendero, C. Tixier, P. Tristant, J. Desmaison, and P. Leprince, "Atmospheric pressure plasmas: A review," Spectrochimica Acta Part B: Atomic Spectroscopy, vol. 61, pp. 2-30, 2006. doi:10.1016/j.sab.2005.10.003

[55] K. Tachibana and T. Nakamura, "Comparative study of discharge schemes for production rates and ratios of reactive oxygen and nitrogen species in plasma activated water," Journal of Physics D: Applied Physics, vol. 52, pp. 385202-385219, 2019. doi.org/10.1088/1361-6463/ab2529

[56] V. Medvecká, D. Kováčik, A. Zahoranová, and M. Černák, "Atmospheric pressure plasma assisted calcination by the preparation of TiO 2 fibers in submicron scale," Applied Surface Science, vol. 428, pp. 609-615, 2018. doi.org/10.1016/j.apsusc.2017.09.178

[57] P. Attri, Y. H. Kim, D. H. Park, J. H. Park, Y. J. Hong, H. S. Uhm, et al., "Generation mechanism of hydroxyl radical species and its lifetime prediction during the plasma-initiated ultraviolet (UV) photolysis," Sci Rep, vol. 5, p. 9332, Mar 20 2015. DOI: 10.1038/srep09332

[58] Q. Xiang, X. Liu, S. Liu, Y. Ma, C. Xu, and Y. Bai, "Effect of plasma-activated water on microbial quality and physicochemical characteristics of mung bean sprouts," Innovative food science and energing technologies, vol. 52, pp. 49-56, 2019. doi.org/10.1016/j.ifset.2018.11.012

[59] S. Topcu and C. Kirda, "Irrigation: Environmental Effects," in Reference Module in Earth Systems and Environmental Sciences, ed, 2013. doi.org/10.1016/B978-0-12-409548-9.05194-0 
[60] I. Moeez, H.-D. Lim, J.-H. Park, H.-G. Jung, and K. Y. Chung, "Electrochemically Induced Metallization of $\mathrm{NaCl}$ : Use of the Main Component of Salt as a Cost-Effective Electrode Material for Sodium-Ion Batteries," ACS Energy Letters, vol. 4, pp. 2060-2068, 2019. DOI: 10.1021/acsenergylett.9b01118

[61] C. G. Sonwane and Q. Li, "Structure and transport properties of nanostructured materials," Journal of physical chemistry b, vol. 109, pp. 5691-5699, 2005. DOI: 10.1021/jp044775w 